\title{
Flora das cangas da Serra dos Carajás, Pará, Brasil: Selaginellaceae
}

Flora of the cangas of the Serra dos Carajás, Pará, Brazil: Selaginellaceae

Luiz Armando de Araújo Góes-Neto ${ }^{1,2}$, Julieta Pallos $^{1} \&$ Alexandre Salino ${ }^{1}$

\begin{abstract}
Resumo
Este estudo trata as espécies de Selaginellaceae registradas nas cangas da Serra dos Carajás, estado do Pará, trazendo descrições, ilustrações, distribuição geográfica e comentários sobre estas. Na área estudada foram registradas duas espécies, Selaginella radiata, a qual possui distribuição restrita à América do Sul, e S. simplex, que está mais amplamente distribuída nos Neotrópicos.
\end{abstract}

Palavras-chave: Amazônia, licófitas, rocha ferruginosa, Selaginella, taxonomia.

\begin{abstract}
This study treats Selaginellaceae species recorded in cangas of Serra dos Carajás, Pará state, bringing descriptions, illustrations, geographical distribution, and comments about these. In the study area two species were registered, Selaginella radiata, which has a restricted distribution in South America, and S. simplex, which is widely distributed in Neotropics.
\end{abstract}

Key words: Amazonia, lycophytes, ironstone rocks, Selaginella, taxonomy.

\section{Selaginellaceae}

Selaginellaceae Willk. é uma família monofilética, monogenérica (Selaginella P. Beauv.), e possui cerca de 800 espécies (Zhou \& Zhang 2015) distribuídas em todas as regiões do mundo, com exceção do continente antártico (Setyawan 2011). Ocorre principalmente nas zonas tropicais, contudo, algumas espécies colonizam as zonas ártico-alpinas (Mickel et al. 2004) e desérticas (Banks 2009) em ambos os hemisférios. No Brasil a família é mais diversificada no bioma amazônico, onde possui cerca de 40 espécies (Góes-Neto, Assis \& Salino, dados não publicados). Na Serra dos Carajás foram registradas seis espécies (Arruda 2014), das quais duas ocorrem em formações rupestres de canga.

\section{Selaginella $\mathrm{P}$. Beauv.}

Por possuírem alta variabilidade intraespecífica e diferenças interespecíficas sempre baixas (Schulz et al. 2013), tornase difícil reconhecer e diagnosticar muitas espécies deste gênero. A grande maioria das espécies brasileiras de Selaginella permanece pouco conhecida, muitas destas com a sua taxonomia bastante confusa (Góes-Neto 2016). Os representantes deste gênero são ervas terrícolas ou rupícolas, raramente epífitas, caracterizadas pela presença de rizóforos, folhas do tipo microfilo, dispostas em quatro fileiras, ou menos comumente em espiral, lígula foliar e esporângios reniformes com deiscência distal completa presentes na axila adaxial dos esporofilos. Das cerca de 800 espécies reconhecidas para este gênero 250-300 ocorrem nos Neotrópicos, com cerca de 90 ocorrendo no Brasil e 24 no estado do Pará (Góes-Neto, Assis \& Salino, dados não publicados.).

\footnotetext{
${ }^{1}$ Universidade Federal de Minas Gerais, Av. Antônio Carlos 6627, Pampulha, 31270-901, Belo Horizonte, MG, Brasil.

${ }^{2}$ Autor para correspondência: lgoes-neto@hotmail.com
} 


\section{Chave de identificação das espécies de Selaginella das cangas da Serra dos Carajás}

1. Microfilos laterais com a margem acroscópica curto a longo-ciliada no $1 / 3$ basal; microfilos dorsais com as margens curto a longo-ciliadas no $1 / 3$ basal, ápice longo-aristado; microfilos axilares lanceolados com as margens longo-ciliadas no $1 / 3$ basal; caule estolonífero; megásporos brancos; indivíduos podendo alcançar mais de $30 \mathrm{~cm}$ de compr. 1.1. Selaginella radiata

1'. Microfilos laterais com a margem acroscópica denticulada no $1 / 3$ basal; microfilos dorsais com as margens denticuladas, ápice acuminado a longo-acuminado; microfilos axilares ovado-elípticos com as margens esparsamente serruladas; caule não estolonífero; megásporos amarelos; indivíduos não alcançando mais de $5 \mathrm{~cm}$ de compr.

1.2. Selaginella simplex

1.1. Selaginella radiata (Aubl.) Spring, Bull. Acad. Roy. Sci. Bruxelles 10: 143, no. 54. 1843.

Lycopodium radiatum Aubl., Hist. P1. Guian. 2: 967, no. 8. 1775.

Fig. 1a-c

Planta terrícola ou rupícola, $15-35 \mathrm{~cm}$ compr. Caule decumbente a ereto, verde a paleáceo, glabro, estolonífero, não articulado. Rizóforos axilares, laterais, ou dorsais, restritos à base do caule. Microfilos laterais ovado-lanceolados, base arredondada a truncada, por vezes assimétrica, porção acroscópica podendo ou não sobrepor o caule, margem acroscópica hialina, curto a longociliada no $1 / 3$ basal, minutamente denticulada em direção ao ápice, margem basioscópica inteira ou com um tufo de 2-3 cílios na base, ápice agudo, superfície superior glabra, levemente rugosa, ocasionalmente com idioblastos obscuros, superfície inferior com idioblastos. Microfilos dorsais ovados a ovado-elípticos, base arredondada, margens hialinas, curto a longo-ciliadas no $1 / 3$ basal, denticuladas nos 2/3 apicais, superfície superior sem idioblastos, estômatos inconspícuos sobre a nervura, ápice longo-aristado. Microfilos axilares lanceolados, base arredondada, sem aurículas, margens longo-ciliadas no $1 / 3$ basal, denticuladas a serruladas em direção ao ápice, ápice agudo. Megásporos brancos.

Material selecionado: Canaã dos Carajás, Serra Sul, S11A, 620'47”'S, 50²5'52”'W, 737 m, 25.IV.2012, A.J. Arruda et al. 1109 (BHCB); S11B, 6²1'21'S, 50 23'26”'W, 20.III.2012, A.J. Arruda et al. 730 (BHCB);

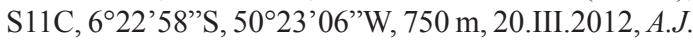
Arruda et al. 725 (BHCB); Serra do Tarzan, $6^{\circ} 19^{\prime} 46^{\prime \prime}$ 'S, $50^{\circ} 07^{\prime} 35^{\prime}$ ”, $740 \mathrm{~m}, 09 . \mathrm{II} .2012$, L.F.A. de Paula et al. 541 (BHCB); Parauapebas, Serra Norte, N2, 603'27'S, 50'14'49”'W, $721 \mathrm{~m}, 19 . \mathrm{IV} .2012$, A.J. Arruda et al. 949 (BHCB); N4-WS, 604'22”S, 50¹1'42”W, 505 m, 24.III.2012, A.J. Arruda et al. 823 (BHCB); N6, 607'22'S, 50¹0'27'W, 674 m, 19.V.2012, A. Salino et al. 15233 (BHCB); N8, 611'11' 'S, 50 07'51”'W, 700 m, 17.V.2012, A. Salino et al. 15206 (BHCB); Serra do Rabo, 6 ${ }^{\circ} 18^{\prime} 46^{\prime}$ 'S, 49 51 '58'W, 713 m, 19.XII.2010, N.F.O. Mota et al. 1986 (BHCB).
Selaginella radiata diferencia-se das espécies congenéricas ocorrentes no estado do Pará por comumente possuir longos cílios hialinos na base dos microfilos, microfilos dorsais com ápice aristado (Góes-Neto et al. 2015), além do caule decumbente a ereto, estolonífero, não articulado, com indivíduos frequentemente discolores, apresentando coloração verde mais intensa na superfície superior e coloração mais pálida (por vezes com aparência prateada) na superfície inferior.

Espécie com distribuição sul-americana, ocorrendo na Colômbia, Equador, Guiana, Guiana Francesa, Suriname e Venezuela. No Brasil ocorre nos estados do Amapá, Amazonas, Maranhão, Mato Grosso, Pará, Piauí e Rondônia. Serra dos Carajás: Serra Norte, Serra Sul, Serra do Rabo e Serra do Tarzan. Na Serra dos Carajás ocorre preferencialmente em áreas de capão, comumente associada a paredões rochosos e a grotões em cachoeiras, ocasionalmente em locais ensolarados associados a cursos d'água ou em áreas de borda na Floresta Ombrófila Densa, entre 275-750 m de altitude.

1.2. Selaginella simplex Baker, J. Bot. 23: 293, no. 304. 1885.

Fig. 1d-f

Planta terrícola ou rupícola, $2-5 \mathrm{~cm}$ compr. Caule subereto, paleáceo, glabro, não estolonífero, não articulado. Rizóforos axilares, restritos à metade basal do caule. Microfilos laterais ovados a ovado-elípticos, base arredondada, porção acroscópica podendo ou não sobrepor o caule, margem acroscópica esverdeada a estreitamente hialina, denticulada no $1 / 3$ basal, serrulada nos 2/3 apicais, margem basioscópica serrulada principalmente na metade apical, ápice agudo, superfície superior glabra, lisa, sem idioblastos, superfície inferior ocasionalmente com idioblastos. Microfilos dorsais ovado-elípticos a ovado-lanceolados, base arredondada, raramente levemente cuneada, margens esverdeadas a 


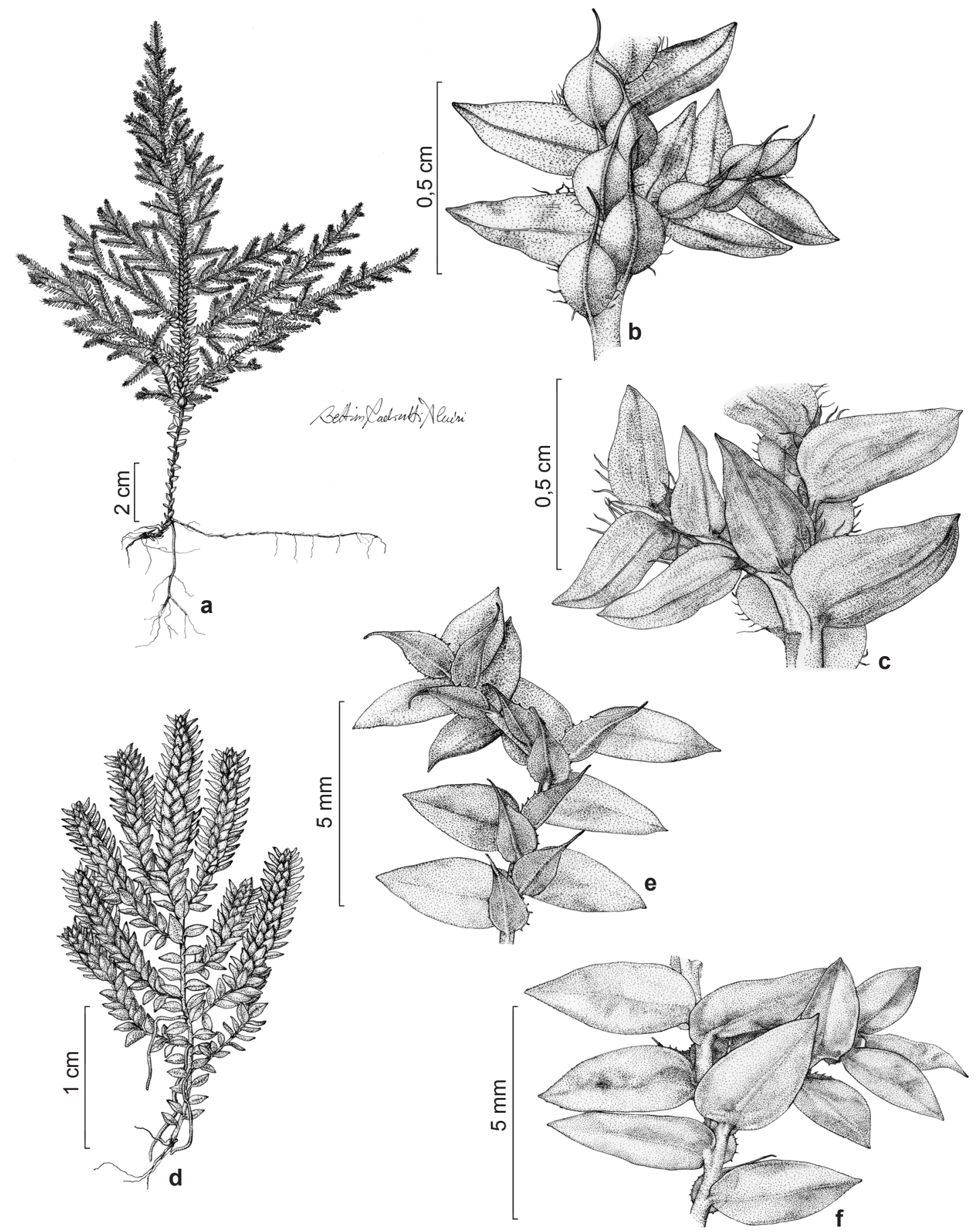

Figura 1 - a-c. Selaginella radiata - a. hábito; b. superfície superior do ramo; c. superfície inferior do ramo. d-f. Selaginella simplex - d. hábito; e. superfície superior do ramo; f. superfície inferior do ramo (a-c. A. Salino et al. 15206; d-f. A. Salino et al. 15256).

Figure 1 - a-c. Selaginella radiata - a. habit; b. upper surface of branch; c. lower surface of branch. d-f. Selaginella simplex - d. habit; e. upper surface of branch; f. lower surface of branch (a-c. A. Salino et al. 15206; d-f. A. Salino et al. 15256). 
estreitamente hialinas, denticuladas, superfície superior sem idioblastos ou estômatos, ápice acuminado a longo-acuminado. Microfilos axilares ovado-elípticos, base arredondada a eventualmente sub-cordada, sem aurículas, margens esparsamente serruladas, ápice agudo. Megásporos amarelos.

Material selecionado: Canaã dos Carajás, Serra Sul, S11A, 618'43”S, 50²7'17’W, 634 m, 22.V.2012, A. Salino et al. 15256 (BHCB); S11C, $6^{\circ} 22^{\prime} 58^{\prime \prime} \mathrm{S}$, 50²3'06”'W, 750 m, 20.III.2012, A.J. Arruda et al. 724 (BHCB); Parauapebas, Serra Norte, N1, 602'29'S, 50¹7’12”W, 684 m, 22.IV.2012, A.J. Arruda et al. 1048 (BHCB).

Selaginella simplex é uma espécie delicada e diminuta, alcançando não mais do que $5 \mathrm{~cm}$ de comprimento. Possui seus microfilos dorsais com cerca de $1 \mathrm{~mm}$ de comprimento, espaçados, esporofilos ventrais curto a longo-ciliados na metade basal e megasporângios distribuídos em duas fileiras ventrais. No estado do Pará, $S$. simplex pode ser confundida com $S$. minima Spring, diferindo por possuir os microfilos laterais com a base acroscópica geralmente não sobrepondo o caule (vs. sempre sobrepondo o caule), denticulada no $1 / 3$ basal (vs. longo-ciliada no $1 / 2(-1 / 3)$ basal) e megásporos amarelos (vs. brancos).

Espécie com distribuição neotropical, ocorrendo na Bolívia, Costa Rica, México, Trindade e Tobago e Venezuela. No Brasil os autores confirmam a ocorrência nos estados de Goiás, Pará e Pernambuco, embora Prado et al. (2015) cite também a ocorrência nos estados do Tocantins, Ceará, Maranhão e Piauí. Serra dos Carajás: Serra Norte e Serra Sul. Na Serra dos Carajás ocorre preferencialmente em matas baixas e campos graminosos sobre a canga, ou ocasionalmente na Floresta Ombrófila Densa, em locais parcialmente sombreados e associados a cursos d'água, entre 605-750 $\mathrm{m}$ de altitude.

\section{Agradecimentos}

Ao CNPq, à bolsa de Pós-Doutorado Júnior concedida a L.A.A. Góes-Neto (proc. 150291/20167). Agradecemos também a bolsa DTI-B concedida a J. Pallos (proc. 380559/2016-1), bem como a bolsa de Produtividade concedida a A. Salino (proc. 306868/2014-8). Ao projeto objeto do convênio MPEG/ITV/FADESP (proc. 01205.000250/201410) e ao projeto aprovado pelo CNPq (proc. 455505/2014-4), o financiamento. Agradecemos também aos revisores anônimos e Thaís E. Almeida, as importantes sugestões oferecidas.

\section{Referências}

Arruda, A.J. 2014. Samambaias e licófitas das serras ferruginosas da Floresta Nacional de Carajás, Pará, Brasil. Dissertação de Mestrado. Universidade Federal de Minas Gerais, Belo Horizonte. 224p.

Banks, J.A. 2009. Selaginella and 400 million years of separation. Annual Review of Plant Biology 60: 223-238.

Góes-Neto, L.A.A. 2016. Estudos taxonômicos em Selaginellaceae Willk. (Lycopodiophyta) no Brasil. Tese de Doutorado. Universidade Federal de Minas Gerais, Belo Horizonte. 254p.

Góes-Neto, L.A.A.; Maciel, S.; Pietrobom, M.R. \& Valdespino, I.A. 2015. Licófitas (Lycopodiophyta) do Corredor de Biodiversidade do Norte do Pará, Brasil. Rodriguésia 66: 229-244.

Mickel, J.T.; Smith, A.R. \& Valdespino, I.A. 2004. Selaginella. In: Mickel, J.T. \& Smith, A.R. (eds.). The Pteridophytes of Mexico. Memoirs of The New York Botanical Garden, New York. Pp. 550-602.

Prado, J.; Sylvestre, L.S.; Labiak, P.H.; Windisch, P.G.; Salino, A.; Barros, I.C.L.; Hirai, R.Y.; Almeida, T.E.; Santiago, A.C.P.; Kieling-Rubio, M.A.; Pereira, A.F.N.; Øllgaard, B.; Ramos, C.G.V.; Mickel, J.T.; Dittrich, V.A.O.; Mynssen, C.M.; Schwartsburd, P.B.; Condack, J.P.S.; Pereira, J.B.S. \& Matos, F.B. 2015. Diversity of ferns and lycophytes in Brazil. Rodriguésia 66: 1073-1083.

Schulz, C.; Homberg, J. \& Stützel, T. 2013. Taxonomic revision of Selaginella subg. Ericetorum. Systematic Botany 38: 5-14.

Setyawan, A.D. 2011. Review: Recent status of Selaginella (Selaginellaceae) research in Nusantara. Biodiversitas 12: 112-124.

Zhou, X.M. \& Zhang, L.B. 2015. A classification of Selaginella (Selaginellaceae) based on molecular (chloroplast and nuclear), macromorphological, and spore features. Taxon 64: 1117-1140.

\section{Lista de exsicatas}

Arruda, A.J. 724 (1.2), 725 (1.1), 730 (1.1), 823 (1.1), 827 (1.1), 949 (1.1), 1048 (1.2), 1109 (1.1), 1111 (1.2); Mota, N.F.O. 1986 (1.1); de Paula, L.F.A 541 (1.1); Salino, A. 15206 (1.1), 15233 (1.1), 15256 (1.2); Viana, P.L. 3403 (1.1). 